\title{
Long-term follow-up on biological risk factors, adiposity, and cardiorespiratory fitness development in a physical education intervention: a natural experiment (CHAMPS-study DK)
}

Jakob Tarp ${ }^{1 *}$ (i), Eva Jespersen ${ }^{2}$, Niels Christian Møller ${ }^{1}$, Heidi Klakk ${ }^{1,3}$, Barbara Wessner ${ }^{4}$, Niels Wedderkopp ${ }^{1,5}$ and Anna Bugge ${ }^{1}$

\begin{abstract}
Background: Schools are a key setting for large-scale primordial non-communicable disease prevention in young people, but little data on sustainability of impacts on cardiometabolic risk markers is available.

Methods: Six and a half year follow-up of a natural experiment. In 2008, six public schools in the municipality of Svendborg (Denmark) augmented their curricular physical education (intervention) and four matched schools served as controls. At long term follow up in $2015 n=312$ participants aged 5-11 years had complete data (33\% of children providing necessary baseline data). The intervention, that consisted of a trebling of weekly physical education lessons and courses provided to physical education teachers, was provided at intervention schools up until 6th grade. Participants attended 6th to 10th grade at follow-up. Differences in the homeostasis model assessment of insulin resistance, blood pressure, triglycerides, cholesterol ratios, cardiorespiratory fitness, waist-circumference, and a composite score of these, between participants attending intervention and control schools were analysed by mixed linear regression models. Differences in physical activity at follow-up was analysed cross-sectionally (no baseline available) in $n=495$.

Results: Compared to controls, children at intervention schools had a non-significant -0.07 ( -0.32 to 0.18$)$ standard deviations lower composite risk score 6.5 years after project initiation. Likewise, no statistically significant differences between intervention and control schools were found for any of the other outcomes ( $p$-values $\geq 0.41$ ). However, six of seven outcomes were in a direction favouring intervention schools. No statistically significant differences between intervention and control schools were observed for physical activity outcomes ( $p$-values $\geq 0.13$ ).

Conclusions: An augmented physical activity program including 270 min of weekly physical education provided for three to seven years did not materialize in statistically significant differences in established risk markers in children from intervention compared to control schools. As the intervention was discontinued after 6th grade, the post-intervention effect of augmented physical education throughout adolescence is unknown. School-based physical activity programs may benefit from incorporating instruments for behaviour translation to leisure time in their intervention models to increase the probability of achieving public health relevance.
\end{abstract}

Trial registration: ClinicalTrials.gov Identifier: NCT03510494.

Keywords: Physical activity, School, Prevention, Cardiometabolic, Blood pressure, Insulin resistance, Lipids

\footnotetext{
* Correspondence: teamtarp07@gmail.com

${ }^{1}$ Research Unit for Exercise Epidemiology, Centre of Research in Childhood

Health, Department of Sports Science and Clinical Biomechanics, University

of Southern Denmark, Campusvej 55, 5230 Odense M, Denmark

Full list of author information is available at the end of the article
}

(c) The Author(s). 2018 Open Access This article is distributed under the terms of the Creative Commons Attribution 4.0 International License (http://creativecommons.org/licenses/by/4.0/), which permits unrestricted use, distribution, and

reproduction in any medium, provided you give appropriate credit to the original author(s) and the source, provide a link to the Creative Commons license, and indicate if changes were made. The Creative Commons Public Domain Dedication waiver (http://creativecommons.org/publicdomain/zero/1.0/) applies to the data made available in this article, unless otherwise stated. 


\section{Background}

Excess adipose tissue accumulation and dysregulated metabolic homeostasis in young people are potentially key markers of increased risk of non-communicable diseases (NCDs) such as cardiovascular disease or type 2 diabetes in adulthood [1-3] and may even predict premature mortality [4]. Physical activity should be considered part of a preventive effort because of its role in energy balance and metabolic regulation $[5,6]$. However, trends indicate that physical activity and cardiorespiratory fitness levels in young people may be declining [7-9] and possibly accelerated in low socioeconomic segments of society [9]. These trends are alarming as a lack of physical activity is a leading cause of premature mortality in the adult population [5] and physical activity levels track from childhood to adulthood [10].

Obesity is highly prevalent in nearly all contemporary societies affecting 671 million adults worldwide in 2016 [11] and with a prevalence range of 18 to $38 \%$ in European and high-income Western countries [11]. Population-wide initiatives to increase physical activity levels and ameliorate obesity related disorders are therefore warranted [12]. As 70\% of obese adults were not obese in their youth [13] preventive actions targeting obese youth will not, even if effective for the individual, prevent the majority of disease burden in the population [14]. School-based approaches have the potential to reach near population-wide coverage as school attendance is mandatory, thus representing an ideal setting for large-scale primordial prevention based on a structural strategy. Structural strategies are appealing as socioeconomic gradients in health inequity may widen with individual-agency approaches $[15,16]$. Physical education led by teachers trained in class-management and provision of quality physical education lessons has the potential to provide students with relatively high physical activity levels during classes [17-20], which may carry to higher physical activity patterns on physical education days [18]. Accordingly, provision of additional physical education led by professionals could be a viable option for increasing physical activity levels of schoolaged children.

Population-based physical activity interventions initiated in schools (implemented as a physical activity only or part of a multicomponent approach) have shown positive benefits on biological risk factors in young people when evaluated immediately post-intervention $[21,22]$ However, there is a scarcity of data on longterm benefits on the risk factors [23]. Long-term evaluation is needed to create evidence informed practice. By implementing an augmented school-based physical education program in 2008 the Childhood Health, Activity, and Motor Performance School study DK (CHAMPS study-DK) achieved reductions in clustering of biological risk factors [24] and lowered overweight/obesity prevalence at intervention schools as compared with control schools when evaluated after 2 years [25]. The purpose of this study is to follow-up on these short-term benefits by investigating long-term (6.5 years) differences between children attending control and intervention schools in the CHAMPS-study DK with a focus on; 1) risk factor clustering and 2) single risk-factors.

\section{Methods}

\section{Setting and study design}

The CHAMPS-study DK is a natural experiment [26] implemented as a controlled intervention study including children from ten public schools (age range: 5-12 years old) in the municipality of Svendborg, Denmark at inception $[17,27]$. The school-years included at baseline are the first year of school (comparable to U.S. kindergarten) to the 4th grade. The CHAMPS-study DK was designed to evaluate a trebling of curricular physical education (from 90 to $270 \mathrm{~min}$ per week distributed across at least three school days), initiated by the municipality of Svendborg. All nineteen schools in the municipality were invited to take part in the study of which six schools were willing and able to fund the additional physical educations classes and became intervention schools. Four schools in the municipality, matched on size, rural/urban and sociodemographic uptake area, agreed to serve as controls. Control schools maintained physical education at the national curricular 90 min per week. Based on summary-level statistics from the National Danish Registry of Statistics, parents at schools participating in the project had approximately $15 \%$ higher household income, but did not differ in educational level, as compared with non-participating schools [28]. There were no differences in summary-level income or the educational attainment of parents between intervention and control schools [17]. The additional physical education was implemented from the start of the school year in August 2008 and evaluated for effects on biological risk factors and adiposity two years later [24, 25]. After 2010, the six intervention schools have maintained their additional physical education now spanning from kindergarten to the 6th grade (6th grade children approximately 12-14 years old). Thus, from 7th to 9th grade (final mandatory school year in Denmark) the "standard" two physical education lessons per week were provided both at intervention and control schools. Hence, interventionschool participants could receive from three (4th grade in 2008) to seven (Kindergarten in 2008) years of additional physical education (detailed in Fig. 1). A national schoolreform mandating $45 \mathrm{~min}$ of physical activity on each school day (not including recess and other breaks) was implemented from the beginning of the 2014/2015 school-year. Implementation of the $45 \mathrm{~min}$ is managed at the school-level. 


\begin{tabular}{|c|c|c|c|c|c|c|c|c|}
\hline School-year at baseline & $2008 / 09$ & $2009 / 10$ & $2010 / 11$ & $2011 / 12$ & $2012 / 13$ & $2013 / 14$ & $2014 / 15$ & School-year at follow-up \\
\hline \multicolumn{9}{|c|}{ Intervention schools } \\
\hline Kindergarten (5-6 years old) & \multicolumn{6}{|c|}{ Six weekly PE lessons } & NSR & $6^{\text {th }}$ grade ( $12-13$ years old $)$ \\
\hline $1^{\text {st }}$ grade & \multicolumn{6}{|c|}{ Six weekly PE lessons } & NSR & $7^{\text {th }}$ grade \\
\hline $2^{\text {nd }}$ grade & \multicolumn{6}{|c|}{ Six weekly PE lessons } & NSR & $8^{\text {th }}$ grade \\
\hline $3^{\text {rd }}$ grade & \multicolumn{4}{|c|}{ Six weekly PE lessons } & \multicolumn{2}{|c|}{ Two weekly PE lessons } & NSR & $9^{\text {th }}$ grade \\
\hline $4^{\text {th }}$ grade $(10-11$ years old $)$ & \multicolumn{3}{|c|}{ Six weekly PE lessons } & \multicolumn{3}{|c|}{ Two weekly PE lessons } & NSR & $10^{\text {th }}$ grade $(16-17$ years old $)$ \\
\hline \multicolumn{9}{|c|}{ Control schools } \\
\hline All & \multicolumn{6}{|c|}{ Two weekly PE lessons } & NSR & $6^{\text {th }}$ to $10^{\text {th }}$ grade \\
\hline
\end{tabular}

Fig. 1 Years of physical education exposure in the CHAMPS-study DK cohort by school-year at baseline and intervention status (2008-2015), Grey boxes indicate six weekly lessons of physical education. Dark boxes indicate two weekly lessons. The NSR mandates 45 min of physical activity on each school-day (not including recess and other breaks). Implementation of the $45 \mathrm{~min}$ is managed at the school-level. PE: Physical education, NSR: national school-reform

\section{Intervention content}

In addition to increased physical education, all physical education teachers (in Denmark physical education is mainly taught by physical education specialists) attended a 40-lesson skill developing course based on an Agerelated Training Concept developed by the Danish organization for elite sports (Team Denmark) [29]. The purpose of this program is to augment development of body and motor skills in children and adolescents by considering their physical, physiological, mental and social development. Shortly put, the program is based on play, exercise and games. The focus on technical and coordinative skills was increased as children entered adolescence. Control schools maintained national guidelines. Pertinent to both intervention and control schools is that physical education in Denmark, in addition to physical activity, also has pedagogical and social aims.

\section{Participants}

In 2008, all children and parents from the ten schools ( $n=1507)$ were invited to participate in the study [24]. In 2015, all 1278 adolescents attending 6th to 9th grade at the same now nine schools (due to merging of schools) were invited to participate in a follow-up study. Recruitment in 2015 was based on handouts at schools, postal mail of study material to parents, and telephone calls by study staff. Additionally, students who had completed mandatory schooling ("10th" grade in 2015 and 4th grade in 2008) with prior participation in the study $(n=179)$ were sought via postal mail and telephone calls. This study reports long-term effects of the CHAMPS-study DK in 312 participants with 6 . 5 years of follow-up. Participants included are those providing fasting values of insulin, glucose and lipids in 2008 and 2015 in addition to information on self-reported sexual maturity at both these time-points. Blood chemistry was required for inclusion as these variables constituted the bulk of missing follow-up data and missingness was considered to abundant to impute the variables. Sexual maturity was required because of its key role in insulin-resistance during adolescence [30, 31]. The CHAMPS-study DK was approved by the ethics committee of the region of southern Denmark (S-20080047 and S-20140105) and written informed consent was obtained from a parent or legal guardian at both time-points.

\section{Outcomes}

Data collection for variables used in this study took place during August-October in 2008 (baseline) and February-May in 2015 (follow-up). At both time-points measurements were performed at schools by trained research staff following standardized procedures but not blinded to control/intervention status. Collection of data on 10th grade participants took place in weekends. Blood samples were obtained following an overnight fast between 08.00 and 10.00 am and analysed for total cholesterol (TC), triglyceride, HDL-cholesterol (HDL-c), glucose and insulin in a ISO 9001:2008 certified routine laboratory associated with the University of Vienna, Austria as detailed elsewhere [24]. Briefly, TC, triglycerides, HDL-c and glucose were assessed on a Cobas C System (Roche Diagnostics GmbH, Mannheim, Germany) while insulin was assessed on an Access Immunoassay System (Beckman Coulter, Inc. Brea, CA, USA) using the respective kits. Intermediate precision was determined using human samples and controls in an internal protocol according to the manufacturers. Coefficients of variation for the controls and samples ranged from 0.6 to $0.8 \%$ for 
$\mathrm{TC}$, from 0.6 to $0.9 \%$ for triglycerides, from 0.5 to $0.8 \%$ for HDL-c, from 0.5 to $0.8 \%$ for glucose, 3.1 to $5.6 \%$ for insulin. Resting blood pressure was measured using appropriate sized cuffs by a Vital Signs Monitor 300 series with Flexiport $^{\mathrm{Tn}}$ Blood Pressure (Welch Allyn, New York, NY, USA) in 2008 and the Omron 705IT (Omron, Kyoto, Japan) in 2015. Participants sat resting in the sitting position for $5 \mathrm{~min}$ before monitoring. At least five subsequent values were recorded with 2 -min intervals until the last three values had become stable. The mean of the last three recordings of systolic blood pressure was used in analysis. Waist-circumference was measured by a measurement band (Seca 201, Seca Corporation, Hamburg, Germany) to the nearest $0.5 \mathrm{~cm}$ across the umbilical cord following a gentle expiration. At least two measurements were performed with a third undertaken if the two differed by more than $1 \mathrm{~cm}$. Cardiorespiratory fitness was assessed using a field-test (Andersen-test) lasting $10 \mathrm{~min}$ with fifteen seconds of intermittent running and pausing. Total distance covered was used to represent cardiorespiratory fitness. Criterion validity (r-squared approximately 0.5 against directly measured maximal oxygen uptake) [32, 33] and test-retest reliability ( $\mathrm{r}$-squared approximately $0.7-0.8$ ) of the Andersen-test are acceptable and have been validated in a subsample of the cohort [32].

\section{Other variables}

Body mass was measured to the nearest $0.1 \mathrm{~kg}$ on an electronic scale (Tanita BWB-800S, Tanita Corporation, Tokyo, Japan) with participants wearing light clothes. Stature was measured to the nearest $0.5 \mathrm{~cm}$ using a portable stadiometer (Seca 214, Seca Corporation, Hamburg, Germany or Harpenden stadiometer (West Sussex, UK)). Both measures were conducted barefoot. Sexual maturity was self-reported by indicating resemblance on five drawings (progressive rating 1-5) of secondary sex characteristics as described by Tanner [34]. Pubic hair was used in boys and breast development in girls. Parents returned mailed questionnaires in 2008 and in 2015. These inquired on the educational attainment of the parents or legal guardians, birthweight of the child, and any (biological) family history of NCDs. When available, data from 2015 was used but in case of non-response or missing answers to the 2015 questionnaire, the 2008 data was used. Physical activity levels were assessed by questionnaires and accelerometry in 2015 only and presented as participation in leisure-time structured physical activity (yes/no), \% moderate-to-vigorous physical activity per day (\%MVPA/day), and mean counts/ minute (protocol and data-reduction details available in Additional file 1.

\section{Data reduction}

The primary outcome of this study is a standardized (mean 0 and standard deviation of 1 ) composite risk score [35] consisting of the homeostasis model assessment of insulin resistance (HOMA-IR) calculated as (insulin in IU/l $x$ glucose in $\mathrm{mmol} / \mathrm{l}$ )/22.5) [36], triglyceride, TC:HDLc-ratio, systolic blood pressure, waistcircumference, and cardiorespiratory fitness. A higher composite score represents an unfavourable risk profile. All variables were standardized by age and sex in separate linear regressions and the residuals averaged. Cardiorespiratory fitness was multiplied by -1 in the composite score. Systolic blood pressure and waistcircumference were additionally standardized for height. Blood chemistry variables in 2015 were additionally standardized for week-day of ascertainment [37] but this information was not available at baseline. Because only $3 \%$ of the sample defined themselves in Tanner-category 3-5 at baseline, the sample was re-coded as being either pre-pubertal (stage 1) or pubertal (stages 2-5). At follow-up, 6\% defined themselves as Tanner-category $1-2$ so this was recoded as stages $1-3$, stage 4 , or stage 5 . Body mass index was calculated as body weight $(\mathrm{kg}) /$ stature (meters)^ 2 and used to define participants according to IOTF weight-status categories [38]. The mother or female guardian's highest completed education was used as a marker of socioeconomic position [39] and recoded (from an abbreviated seven-level instrument based on a Danish adaptation of the International Standard Classification of Education 2011) to; 0 (no tertiary qualifications) or 1 (any tertiary qualifications). Indication of family history of diabetes (any type), cardiovascular disease (any type) or hypertension in siblings, biological parents or grandparents, were combined into; 0 (no) or 1 (yes). Birthweight was used in continuous form.

\section{Statistics}

Baseline characteristics between intervention and control schools were compared using an unpaired t-test for normal distributed continuous data or Wilcoxon ranksum test for non-normal distributed data. A chi-squared test was used for categorical data. Details of comparisons between the analytical sample and those lost to followup using data obtained in 2008, 2010, 2012, 2013, and 2015 are available in Additional file 2.

\section{Statistical analysis of primary and secondary outcomes}

Differences between intervention and control schools are presented as composite risk score at follow-up, using control schools as reference, analysed in linear mixed models controlled for baseline values of the respective outcome. In secondary analyses, individual outcomes are analysed using the same approach. Results are presented with 95\% confidence intervals (CI). Models additionally included the covariates age, sex, sexual maturity (in 2008 and 2015), educational attainment of the mother or female legal guardian, birthweight, and family history of 
NCDs. A random intercept for school-class at baseline was included. Random intercepts for school-class or school at follow-up were not included as little variance was explained by these terms. Analysis was performed based on participant's intervention status at baseline irrespective of their follow-up school membership. Six of ten schools covered kindergarten to 9th grade (no reallocation from primary to secondary school), while four schools (two control and two intervention) included kindergarten to 6th grade only. Of these four schools, students from intervention schools were allocated to other intervention schools, while students from one control school were allocated to an intervention school while students from the other control school were allocated to a school outside of the project. To explore if additional physical education had a distinct effect among those with the least favourable metabolic profiles, participants at control and intervention schools were stratified at the baseline median and analysed separately in secondary analyses. Stratification was performed for each outcome. Physical activity was analysed using the same control variables as the composite risk score but without baseline-adjustment as this data was not available. These analyses used a logistic regression model for structured leisure-time physical activity, and included indicators for the number of total days and weekdays included in models of \% MVPA/day and mean counts/min. Participants were included in analysis of physical activity if they; had provided informed consent during the initial phase of the study (2008-2010), at the follow-up in 2015, provided either subjective or objective physical activity data, and had anthropometrical or physical performance data to inform imputation models $(n=495$, full details available in Additional file 1).

\section{Model diagnostics and imputation of missing variables}

Linear regression diagnostics were performed by visually inspecting normality and homoscedasticity of model residuals (assumptions met), checking influential observations by calculating the dfbeta (interpretation of results not affected), and visually verifying normal distribution of random intercepts (assumption met). HOMA-IR, triglyceride, TC: HDL-c ratio, waist-circumference and cardiorespiratory fitness were skewed and transformed by the natural logarithm prior to standardization. Missing values ( $n=3$ to 33 ) of variables other than blood chemistry and sexual maturity were imputed by chained equations (MICE), which is detailed in Additional file 2. As follow-up data is collected as an extension of the original study, no power calculations were performed prior to participant recruitment. TREND and TIDieR checklists are available in Additional file 3: Table S4 and Additional file 4: Table S5. Analysis was conducted in Stata v.15.0 (StataCorp, College Station, TX, USA). A two-sided alpha at the 0.05 level was used to indicate statistical significance.

\section{Results \\ Missing data}

In 2008, 1209 students provided informed consent of which a fasting blood sample was available in 959 (64\% of invited). In 2015, 745 students (irrespective of previous contact with the study) consented and 580 (40\% of invited) provided a fasting blood sample. A total of 312 participants, with a fasting blood sample and information on sexual maturity at both time-points, were available for long-term follow-up (analytical sample: $21 \%$ of invited and $33 \%$ of those who obtained fasting blood samples in 2008). Of those invited in 2008, 18 and 31\% of participants were available for long-term follow-up at control and intervention schools, respectively. Please refer to Fig. 2 for flow-chart as well as in Additional file 2: Table S1 for school-year specific loss to follow-up. The analytical sample differed from their peers unavailable for follow-up, in that the former was younger $-0.75(-0.57$ to -0.93$)$ years, and characterized by more favourable anthropometric and cardiorespiratory fitness characteristics (baseline body mass index $-0.40(-0.68$ to -0.12$)$ points, waist-circumference -1.30 (-2.11 to -0.49$)$ centimetre, and cardiorespiratory fitness 19 (5 to 32) meters. Indications of non-identical missingness characteristics between intervention and control schools were observed for family history of NCDs $(p=0.07)$, educational attainment of the mother or female legal guardian $(p=0.03)$, and pubertal development in $2012(p=0.02)$. No evidence to suggest differential missingness characteristics were found for anthropometric variables, the composite risk score, or cardiorespiratory fitness at any time-point ( $p$-values $>0.34)$.

\section{Characteristics of the analytical sample}

Baseline (2008) characteristics of the analytical sample are shown in Table 1 . In the analytical sample, $56 \%$ of intervention school participants were girls while this was the case for $44 \%$ of analysed participants at control schools ( $\mathrm{p}$ for gender difference $=0.06$ ). At baseline, participants at intervention schools had a 1.79 (0.06 to 3.53) $\mathrm{mmHg}$ higher systolic blood pressure, but a 19\% lower HOMA-IR score. The prevalence of overweight or obesity was $8.4 \%$ in 2008 and $6.8 \%$ in 2015 with no difference between intervention and control schools ( $p$-values $\geq 0.21$ ).

\section{Primary and secondary outcomes}

Figure 3 presents differences in the outcome variables at follow-up between intervention and control schools. The difference in composite risk score did not reach statistical significance (standardized beta with 95\% CI) -0.07 $(-0.32$ to 0.18$)$. Likewise, differences were nonsignificant for the individual risk factors $(p$-values $\geq 0.41$ ) 


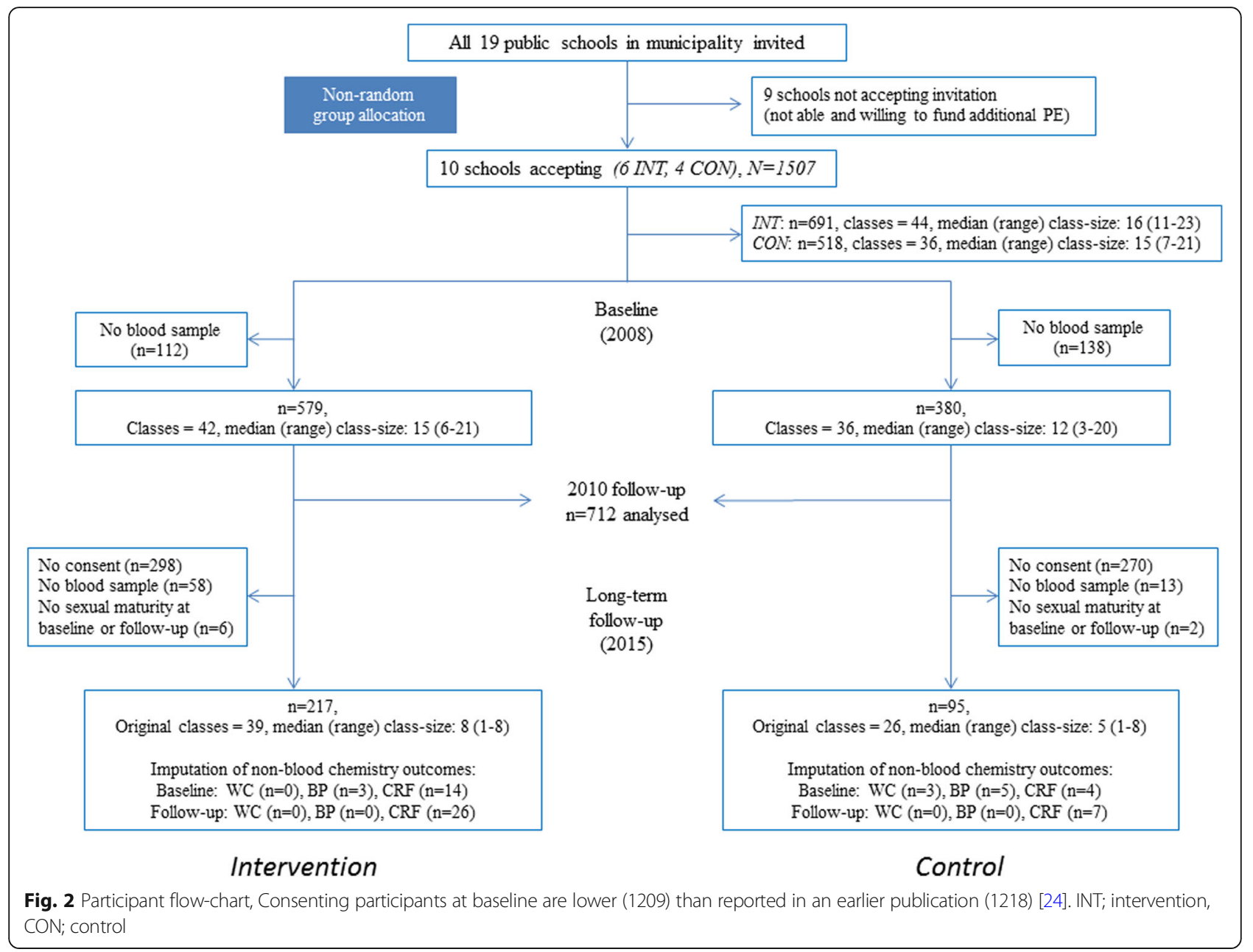

with standardized betas ranging from $-0.10(-0.39$ to 0.20$)$ for cardiorespiratory fitness to $-0.03(-0.25$ to 0.19$)$ for waist-circumference. All associations, although not significant, favoured intervention schools, except for cardiorespiratory fitness. In un-transformed scales, differences between intervention and control schools were $-0.3(-2.1$ to 1.5$) \mathrm{mmHg},-0.2$ (- 1.6 to 1.2$)$ centimetres, and -9 ( -39 to 20$)$ meters for systolic blood pressure, waist-circumference and cardiorespiratory fitness, respectively. For blood chemistry variables, differences expressed in untransformed scales were $-0.03(-0.12$ to $0.06) \mathrm{mmol} / \mathrm{l},-0.08$ ( -0.24 to 0.08$)$, and -0.10 ( -0.33 to 0.14) for triglycerides, TC: HDL-c ratio and HOMA-IR, respectively. Figure 4 depicts a visual illustration of the 2 and 6.5 year (analysed in this study) development of the biological risk factors in the CHAMPS-study DK.

In analyses with outcomes stratified at the median baseline-level (Fig. 5), the least favourable half at intervention schools presented, compared to the least favourable half at control schools, a $-0.17(-0.55$ to 0.20$)$ standard deviation lower composite score at follow-up albeit the difference did not reach statistical significance. No statistically significant differences were observed for the individual risk factors. Effect-sizes for (standardized) outcomes stratified at the median ranged from $-0.32(-0.67$ to 0.02 ) for HOMA-IR and -0.26 (-0.62 to 0.10$)$ for waist-circumference to 0.05 ( -0.31 to 0.41$)$ for systolic blood pressure. When analysing physical activity levels as assessed in 2015 from $n=495$, neither structured participation in leisure-time physical activity (odds ratio: $0.79(0.46$ to 1.36$)$ ), \%MVPA/day (unstandardized beta: -0.17 ( -0.67 to 0.33 )), or mean counts/minute (unstandardized beta: -25 (-58 to 8$)$ ) differed statistically significant between intervention and control schools.

\section{Discussion}

This study evaluated a natural experiment based on a trebling of curricular physical education from 90 to 270 weekly minutes at intervention schools compared to controls. In spite of a demonstrated 2-year efficacy of the intervention, the data did not support sustainability of favourable clustered or single risk factor adaptations comparing intervention with control schools after 6.5 years. 
Table 1 Baseline characteristics of participants

\begin{tabular}{|c|c|c|c|c|c|}
\hline & $\mathrm{N}$ & Intervention & $\mathrm{n}$ & Control & $\begin{array}{l}p \text {-value for between } \\
\text { school-type difference }\end{array}$ \\
\hline Age (years) & 217 & $7.8(1.3)$ & 95 & $7.8(1.3)$ & 0.98 \\
\hline Sex (\% girls) & 217 & 56 & 95 & 44 & 0.06 \\
\hline Stature $(\mathrm{cm})$ & 216 & $129.2(8.8)$ & 92 & $128.8(9.7)$ & 0.71 \\
\hline Body weight (kg) & 217 & $26.8(5.4)$ & 92 & $26.9(5.9)$ & 0.94 \\
\hline Sexual maturity (\% tanner stage 1 ) & 217 & 75 & 95 & 79 & 0.38 \\
\hline Mothers educational attainment (\% any tertiary) & 210 & 65 & 92 & 58 & 0.24 \\
\hline Family history of NCDs (\% yes) & 211 & 50 & 92 & 53 & 0.58 \\
\hline Birthweight (gram) & 298 & 3495 (711) & 91 & $3481(550)$ & 0.87 \\
\hline Composite score (z-scores) & 200 & $-0.07(0.97)$ & 89 & $0.17(1.05)$ & 0.06 \\
\hline Cardiorespiratory fitness (meters) & 203 & $887(101)$ & 91 & $885(107)$ & 0.84 \\
\hline Systolic blood pressure (mmHg) & 214 & $100.1(6.5)$ & 90 & $98.3(8.2)$ & 0.04 \\
\hline Waist-circumference $(\mathrm{cm})^{\mathrm{a}}$ & 217 & $55.0(52.5-58)$ & 92 & $56.5(53-61.3)$ & 0.08 \\
\hline HOMA-IR & 217 & $0.54(0.37-0.75)$ & 95 & $0.65(0.47-0.89)$ & 0.004 \\
\hline Triglyceride $\left(\mathrm{mmol} / \mathrm{l}^{\mathrm{a}}\right.$ & 217 & $0.58(0.46-0.71)$ & 95 & $0.56(0.47-0.71)$ & 0.79 \\
\hline TC:HDL-c-ratio ${ }^{a}$ & 217 & $2.6(2.3-3.0)$ & 95 & $2.6(2.4-3.0)$ & 0.51 \\
\hline
\end{tabular}

Mean (standard deviation) is given unless otherwise noted

${ }^{a}$ Median (25th-75th centile). NCD non-communicable diseases, HOMA-IR homeostasis model assessment of insulin resistance, TC total cholesterol, HDL-C High-density lipoprotein cholesterol

At the 2-year follow-up of the CHAMPS study-DK, the intervention was associated with a favourable composite risk score and lower triglyceride and systolic blood pressure levels [24]. Short-term or immediate post-intervention positive benefits on biological risk factors may be achieved with school-based physical activity interventions [40-44]. It is noticeable that in some studies a positive benefit appears without concomitant effects on adiposity indices [40, 42-44]. Other positive post-intervention benefits of school-based physical activity initiatives may include higher cardiorespiratory fitness [45] and lower obesity levels [46]. Beneficial adaptations are however not universal $[47,48]$ which calls for identification of those intervention features (or feature combinations) associated with intervention efficacy [49]. Considering the evidence-base as a whole, school-based physical activity interventions suffer from methodological weaknesses particularly in relation to attrition,

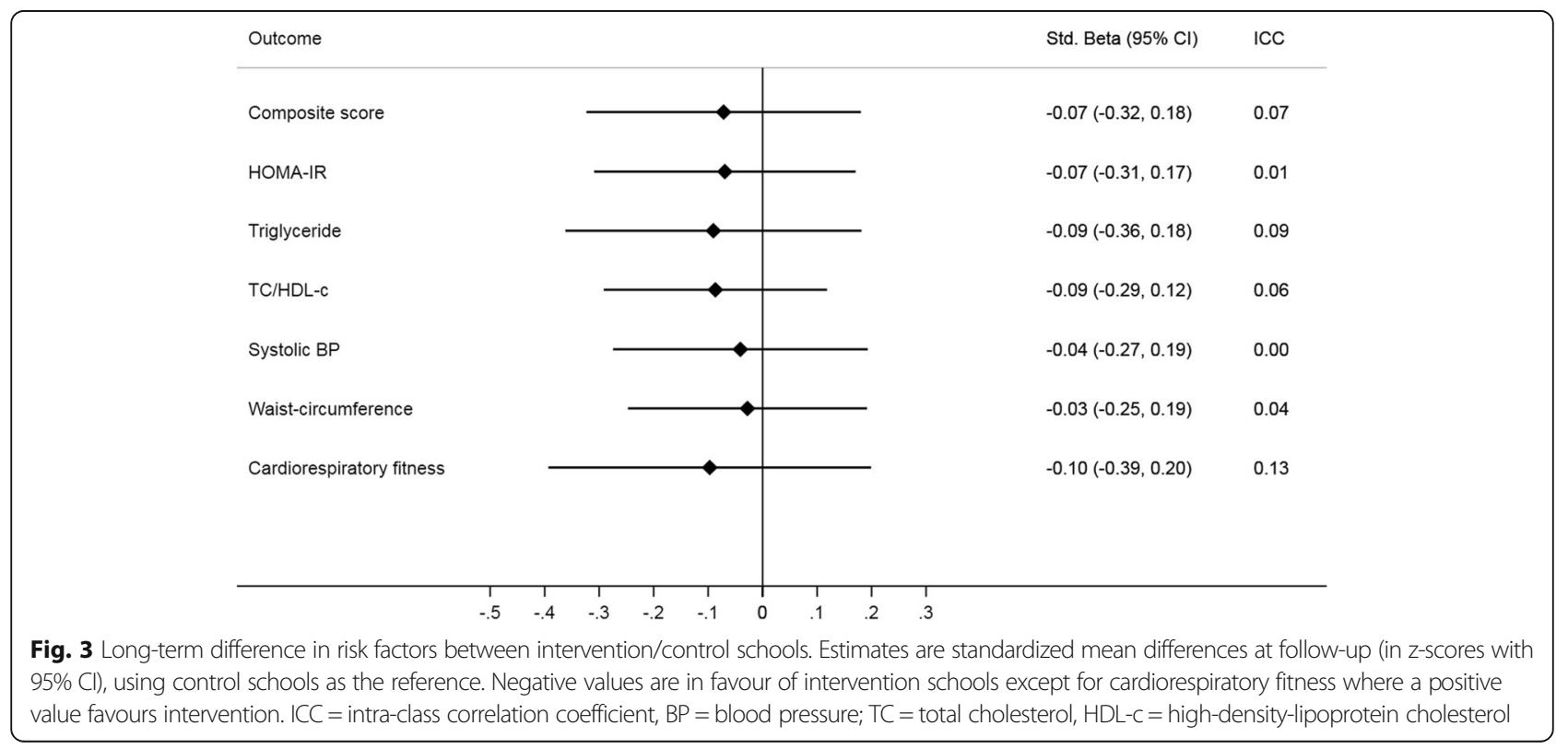




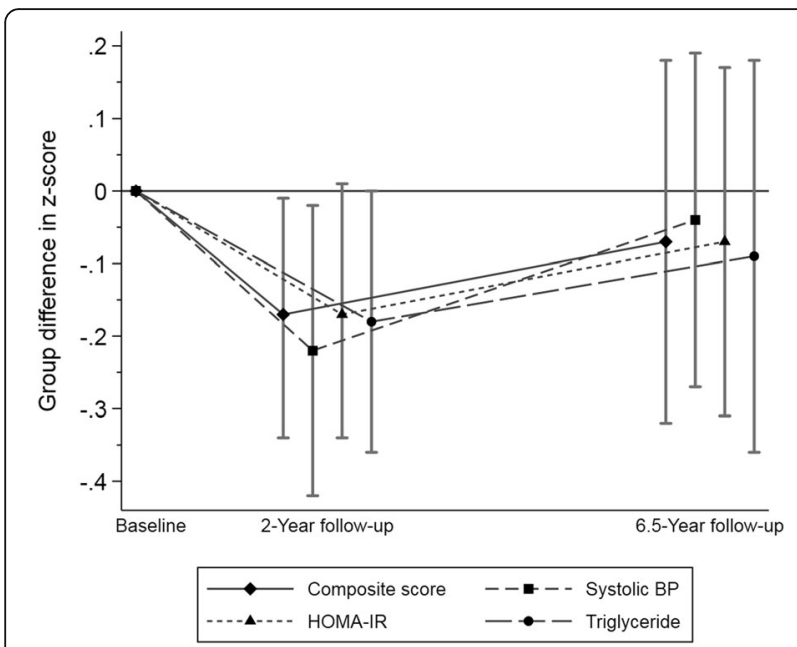

Fig. 4 Illustration of difference in biological risk factor development between intervention/control schools in the CHAMPS study-DK (2008, 2010, and 2015). Estimates are mean difference between intervention and control school with a $95 \% \mathrm{Cl}$. Negative values favour intervention group. Two-year follow-up estimates are from an earlier publication with 712 participants analysed [24]. 6.5 year follow-up are estimates from the 312 participants in this manuscript. Confidence intervals not overlapping zero are statistically significant. Baseline group-differences set to zero as results are presented as adjusted difference in change including baseline-value of outcome, which provides the interpretation that group-mean values are identical at baseline lack of blinding of outcome assessors, and incomplete description of the randomization process (if relevant) [23]. This study is not exempt from these limitations. The difficulties in achieving strong methodological rigor in the school-based setting are exemplified by the AFLY5-study [50]. This large cluster-randomized controlled trial made substantial efforts in achieving methodological rigor but remained highly susceptible to selection-bias as more than $40 \%$ of participants had incomplete data on the main outcome.

\section{Comparison with existing studies including a longer-term follow-up}

Post-interventional successes apart, our data did not support maintained intervention benefits over time. This is in contrast with two similar studies with data on longterm follow-up on biological risk factors, which do provide tentative support of positive sustainable benefits. These studies were based on provision of additional physical education and have evaluated both immediate post-intervention and long-term follow-up difference between intervention and control schools [41, 42, 51]. The CoSCIS study was a non-randomized controlled intervention based on a doubling of weekly physical education from 90 to $180 \mathrm{~min}$ for 3 years in addition to provision of outdoor play-ground equipment. The CoSCIS trial observed

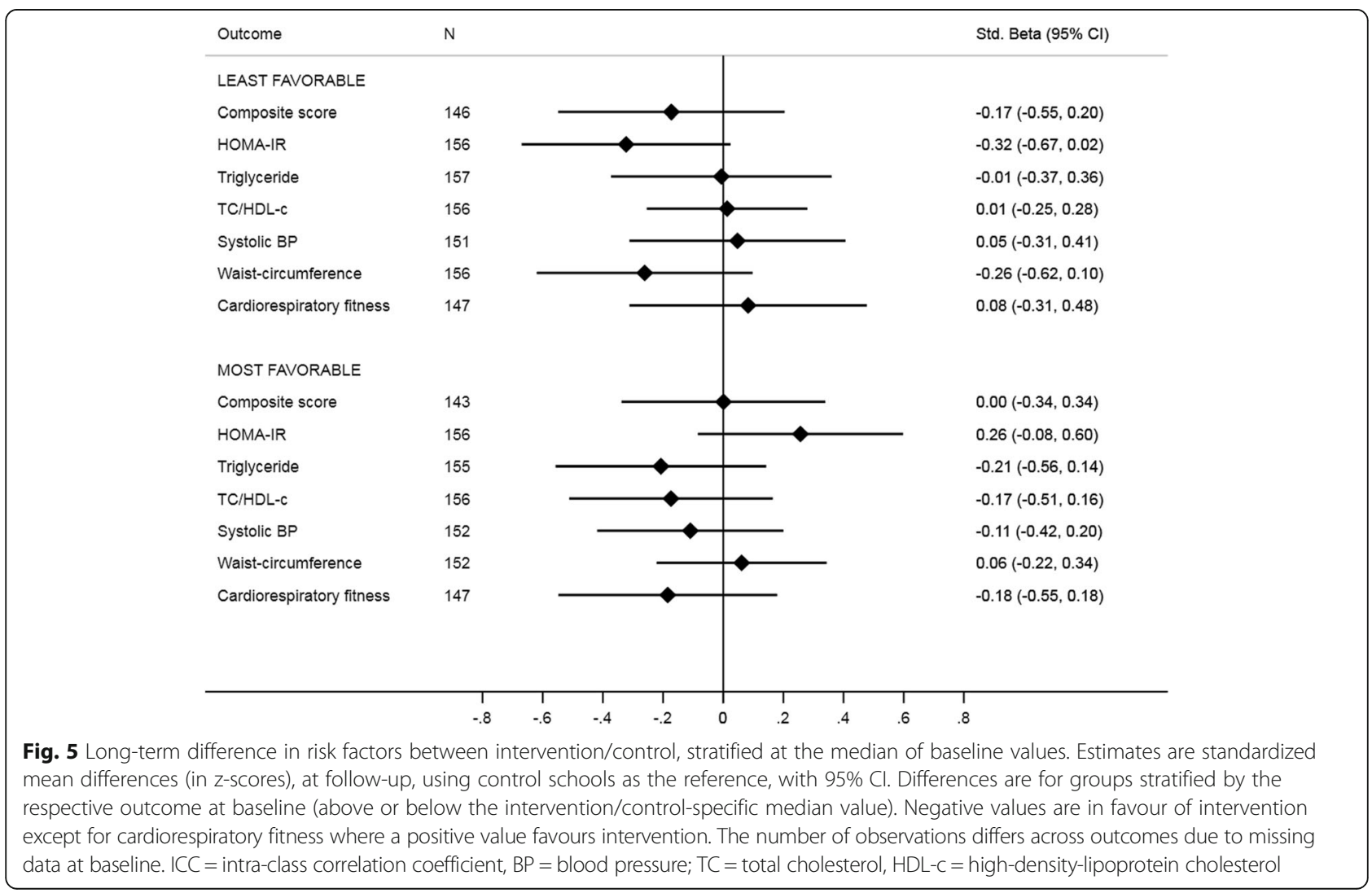


higher insulin sensitivity in intervention school boys postintervention and an approximately $3 \mathrm{mmHg}$ lower systolic blood pressure change in boys when followed-up 4 years after the intervention had ceased [42]. No differences between intervention and control school girls were observed at any time point. At the 4-year follow-up of the KISS randomized controlled trial which included nine months of augmented (lesson content) and expanded (from 135 to 225 min weekly) physical education curriculum at its core, participants at intervention schools had a substantially higher cardiorespiratory fitness (5\% difference) and greater participation in leisure-time sports compared to participants at control schools [51]. At follow-up, only one risk factor was affected, which was in contrast to the postintervention evaluation where several metabolic markers (composite score, HDL-cholesterol, triglyceride, glucose), cardiorespiratory fitness, and body composition were favourably modified by the intervention [41]. Long-term differences between intervention and control schools are particularly interesting in the light of the discontinued interventional support in both of these studies. However, even though these sustainable differences would have public health relevance if further maintained over time, statistical significance of results amounts to only one of eleven [42] and one of fourteen [51] investigated outcomes. Thus, in conjunction with high rates of attrition (439 of initially 694 participants [42] and 293 of initially 502 participants [41] available for long-term follow-up, (these losses apart from post-randomization but pre-baseline drop-out)), a cautious interpretation of cause and effect is warranted. Intervention "dose" does not appear to explain the apparent lack of sustained benefits in the CHAMPS-study DK in comparison with the CoSCIS and KISS studies. The CHAMPS-study DK provided an additional $3 \mathrm{~h}$ of physical education per week in the intervention group which was double the dose of additional physical educations as delivered in the CoSCIS study. The KISS study was based on daily 45 min of augmented physical education but in comparison with the control condition, only an additional 90 min per week was added. As effects of physical education on physical activity levels do not appear to extend beyond the days when physical education is taking place [18] this could suggest intervention content should be delivered daily. Accordingly, the Sogndal Study was based on 60 daily minutes of physical activity and achieved remarkable effects on biological risk factors [40]. However, a fairly small Icelandic study providing $60 \mathrm{~min}$ of daily physical activity in the intervention group did not observe any effect on cardiovascular risk markers after 2 years of intervention [48]. The Cretan Health and Nutrition Education Programme provide further support that sustainable benefits of quality physical activity in school can be achieved. Following 6 years of a comprehensive school health programme (diet, physical activity, and risk behaviours), in which augmented physical education (two lessons per week) was one component, differences between intervention and control schools in blood cholesterol and blood pressure were maintained 4 years post-intervention $[52,53]$. Selection bias (attrition and non-randomization) appears the major threat to the validity of the long-term follow-up of the Cretan Health and Nutrition Education Programme. Noticeably, control schools in the Cretan study did not receive any structured physical education for the first half the intervention period which may limit generalizability of the study to a large number of school systems. Conversely, an Australian twenty-week randomized controlled trial including daily twenty minutes fitness sessions did not results in immediate or six-months post-intervention effects on blood pressure or cholesterol levels in high- or low risk children [54]. The internal validity of the Australian study appears robust to selection bias owing to randomization and low attrition. However, the observed lack of shortterm effectiveness is potentially explained by the apparently non-trivial time-frame from cessation of the intervention to collection of post-intervention data. Also, the change in BMI appeared larger in intervention group boys as compared to boys in the control condition.

\section{Public health relevance}

Effect sizes presented in this manuscript can be interpreted as standardized effect-sizes (Cohen's d) which for all outcomes, following Cohen's suggestions, are interpreted as small (and statistically insignificant). A key question is how large a difference in a population-level risk factor is needed to achieve a meaningful public health impact, and by extension, what is the necessary size of effects from school-based initiatives for this to be considered a viable adjunct to a multisectoral population-wide policy change? In a model-based study, even a $1 \mathrm{mmHg}$ population-wide systolic blood pressure reduction in adults may have a profound effect on the total number of cardiovascular disease cases, surpassing that of reducing the prevalence of uncontrolled hypertension by 10\% [55]. As hypertension control programmes operates at sizeable cost [56] and high blood pressure is a leading cause of disability-adjusted life-years [57], even fairly small reductions in blood pressure from school-based approaches are likely public health relevant. Although not a direct contrast between adult hypertension control programmes and augmented school-based physical education, a modelbased simulation on U.S. data suggests population-wide augmented physical education in public schools is a costeffective method for reducing the burden of high bloodpressure attributed cardiovascular disease [58]. When considering the totality of evidence from school-based obesity prevention programs in the general population (including diet, physical activity and combined interventions), two recent meta-analyses reported comparable 
short term systolic blood pressure reductions of 1.64 ( $95 \%$ CI: 2.56 to 0.71 ) [22] and 1.95 (2.85 to 1.05 ) [59] $\mathrm{mmHg}$. Our long-term follow-up did not support such effect-sizes as the systolic blood pressure at intervention schools was $0.22 \mathrm{mmHg}$ lower (statistically insignificant) as compared to control schools.

\section{Do physical activity interventions increase overall physical activity levels in young people?}

The CHAMPS-study DK intervention was associated with relatively high physical activity levels during physical education [17]. No differences in mean physical activity intensity or percentage of time spent at MVPA during physical education were observed between intervention and control schools but the volume delivered was, by design, higher at intervention schools. This suggests the aim of increasing the volume of physical activity in school was accomplished and the intervention thereby implemented satisfactory [17]. Part of the intervention was based on teacher training focusing on an age-related physical education content. Unfortunately we do not have data on qualitative features of delivered content besides time spent above established physical activity intensity thresholds. We note that in Denmark physical education teachers are content-professionals and not e.g. class-room teachers. Thereby quality physical education is also expected at control schools. Despite the appearance of intervention effects on school-time physical activity levels and achievement of favourable metabolic profiles at intervention schools, no differences in total physical activity levels between intervention and control schools were evident during the first 2 years of the study [17]. Similarly, in the cross-sectional analysis of physical activity levels in 2015, which unfortunately lacked baseline data to provide a longitudinal interpretation, we did not observe different physical activity levels at intervention schools as compared to control. As the additional physical education lessons were discontinued after the 6th grade it is possible that the lack of long-term differences between intervention and control schools may owe to the intervention not having resulted in the necessary motivation and/or skills to compensate for the removal of physical education lessons (e.g. by intervention schools students increasing out-of-school physical activity). The creation of lasting habits is likely necessary for school-based initiatives to result in meaningful health benefits. In this light, strictly school-based interventions build solely on increased provision of structured physical activity but without an instrument for translation of behaviour into discretionary time may, although efficacious in increasing physical activity when the intervention is delivered $[17,18,60]$, not provide the necessary impetus to increase physical activity external to the intervention. Reductions in leisure-time sports participation at intervention schools is a potential co-intervention from adding additional school hours and physical education classes. As sports participation is associated with a favourable risk factors profile [61] the direction of such a hypothetical reduction in physical activity in discretionary time would likely be towards a zero effect of the intervention. Our analysis of group means did not support the occurrence of such an effect, but this does not preclude unintended co-interventions in some sub-groups of the sample. In the short term, particularly promising effects of schoolbased interventions including a family component have previously been highlighted. This could relate to a supportive environment $[45,62,63]$ for adapting leisuretime physical activities and thus formation of lasting habits. Data to facilitate short-term intervention efficacy is increasing [49] but without evaluation of which intervention components associates with long-term behavior modification, information to guide public health policy will remain limited. Taken together, there have been limited identification of factors (or their combinations) leading to efficacious interventions $[49,64]$ and particularly to sustainability of achieved success over time [64]. With regards to physical activity levels evidence from twelve randomized controlled trials in youth above 10 years of age in fact suggests objectively measured overall physical activity levels are not increased by current school-based interventional approaches, although some heterogeneity exists [65]. A review also including subjective physical activity assessments came to the reverse conclusion, but given the possibility of recall and socialdesirability bias in self-reported data and the generally unconvincing quality of included studies, these results should be interpreted with caution [23]. In a comprehensive meta-analysis pooling thirty studies including an objective physical activity assessment (accelerometry only) increases in physical activity from interventions were in the order of $4 \mathrm{~min}$ of MVPA/day [66]. The results of two recent meta-analyses of interventions including a "long-term" follow-up, defined as minimum 6 months and 4 weeks post-intervention, both conclude there is a lack of evidence to suggest sustainable effects on physical activity levels $[67,68]$. The apparent lack of even short-term effects on physical activity is in contrast to interventional effects on the biological risk factors and may relate to measurement error and larger attrition rates for physical activity outcomes. Alternatively, changes in dietary behaviours as a consequence of the intervention (intended or not), may explain the discrepancy.

\section{Limitations}

The present study should be interpreted in the light of several limitations. The non-randomized design precludes a causal interpretation, and although matching of 
schools was performed, the possibility of selection bias remains. Analyses were adjusted for potential demographic and biological confounders but information on e.g. nutritional behaviours was not available. Thereby potential confounding from dietary habits or other unmeasured and unbalanced variables cannot be eliminated. Selection bias may also be introduced as missing data was frequent, particularly for the oldest participants. Comprehensive analyses comparing included and non-included individuals at baseline and over time revealed favourable anthropometric and cardiorespiratory fitness profiles in the included sample as compared to the sample lost to follow-up. This could have reduced the potential for beneficial intervention-related adaptations to occur as, in the 2-year evaluation of the study, particularly strong effects were observed in the half presenting the least favourable metabolic profile [24]. Importantly, no evidence of differential missingness characteristics in these variables across intervention and control participants was observed albeit this does not eliminate the possibility of selection bias. Because the intervention was embedded in the school curriculum it was not possible to collect true pre-intervention data. Instead this was obtained up to 2 months after intervention initiation. Accordingly, differences in baseline clinical characteristics, and particularly insulin sensitivity, between intervention and control participants could be the result of early adaptations to the increased physical education lessons. If this is the case, controlling for baseline values could be considered conservative [69]. When analyses of follow-up HOMA-IR and compositescore were repeated without including the baseline values, coefficients were roughly doubled (in favour of intervention), but remained statistically insignificant (data not shown). Although the available sample size was similar to previous studies with a long-term followup, it must be considered low with only 95 participants in the control group available. Hence, the possibility of a type II error cannot be ruled out. Sample size consideration was also the reason no subgroup analysis according to years of intervention exposure was pursued. Multiple imputation was used to retain sample-size, but the number of individuals with missing data on blood samples at follow-up was too large to meaningfully impute this information. The implementation of a nationwide school-reform mandating $45 \mathrm{~min}$ of physical activity on each school day from 2014 could reduce heterogeneity in the participating school children's exposure to physical activity. This could potentially mask effects of an earlier intervention by affecting activity patterns at both control and intervention schools. However, when performing research within the educational system, and particularly when including a prolonged follow-up period, changes to school-policies or the school environment (e.g. ban of purchasing sugar-sweetened beverages at schools, new safer roads for active commuting, new playground equipment) mandated at the school or national level is likely the norm. Such structural changes exemplifies the difficulties in conducting research in an uncontrolled environment were strict adherence to studyconditions are not possible. Finally, because the municipality of Svendborg considered the intervention to be highly successful, in 2012 the additional physical education was implemented at all schools in the municipality (including control schools). However, because the additional physical education was provided to children starting in kindergarten from the school year 2012, children serving as controls in this study would not be directly affected.

\section{Conclusions}

Despite 2-year intervention efficacy, a trebling of curricular physical activity from kindergarten to 6th grade did not result in statistically significant reductions in clustered or single biological risk factors between intervention and control schools, when evaluated after 6.5 years of follow-up. Future research featuring school-based physical activity interventions should 1) pre-plan for long-term follow-up, 2) actively seek to minimize attrition over time, and 3) incorporate instruments for behaviour translation to leisure time into their physical activity intervention models to increase the probability of long-term effects on population health.

\section{Additional files}

Additional file 1: Description of methodology used for physical activity assessment, data-reduction, and imputation of missing variables in cross-sectional analysis of follow-up physical activity levels. (PDF 345 kb)

Additional file 2: Information on multiple imputation procedure, missing data by school-year (Table S1), and comparison between participants available for long-term follow-up and those unavailable for follow-up (Table S2 and S3). (PDF $382 \mathrm{~kb}$ )

Additional file 3: TREND checklist in Table S4. (PDF $435 \mathrm{~kb}$ )

Additional file 4: TIDier checklist in Table S5. (PDF 464 kb)

\section{Abbreviations}

CHAMPS-study DK: Childhood Health, Activity, and Motor Performance School Study Denmark; Cl: Confidence interval; HDL-c: High-densitylipoprotein cholesterol; HOMA-IR: Homeostasis model assessment of insulin resistance; MVPA: Moderate-to-vigorous physical activity; NCD: Noncommunicable disease; TC: Total cholesterol

\section{Acknowledgements}

The authors gratefully acknowledge the work of numerous students and PhD students who have participated in the data collection for the CHAMPS study-DK. We thank children, parents, and teachers in the schools involved in the project, and we are grateful for the cooperation with the Svendborg Project, Sport Study Sydfyn, and the municipality of Svendborg. We thank members of the CHAMPS study-DK not listed as co-authors of this paper: C. T. Rexen, C. Franz, M. Heidemann, L. R. Larsen, T. Junge, L. K Lundberg, M. Rønne, and R. A. Lima for their

invaluable contribution to the project. Finally, we acknowledge the efforts by M. S. Hansen from the Municipality of Svendborg in coordination and facilitating information with schools and biomedical laboratory technicians K. Kjær and D. M. Flindt for their invaluable and dedicated work in collecting, handling and storing the biological material. 


\section{Funding}

The CHAMPS-study DK 2015 follow-up was funded by The TRYG Foundation (grant number: 104982). JT was funded by The TRYG Foundation (grant number: 104982) while contributing to this work. AB has received funding by The TRYG Foundation (grant number: 104982). NCM has received funding by The TRYG Foundation (grant number: 104782). HK was funded by a European Research Council grant. NW and the CHAMPS-study DK has received funding by The TRYG Foundation, University College Lillebaelt, University of Southern Denmark, The Nordea Foundation, The IMK foundation, The Region of Southern Denmark, The Egmont Foundation, The A.J. Andersen Foundation, The Danish Rheumatism Association, Østifternes Foundation, Brd., Hartmann's Foundation, TEAM Denmark, The Danish Chiropractor Foundation, and The Nordic Institute of Chiropractic and Clinical Biomechanics.

\section{Availability of data and materials}

Data are available upon request from the CHAMPS Study Steering Committee due to legal and ethical restrictions. Interested parties may contact Dr. Niels Wedderkopp (nwedderkopp@health.sdu.dk) or Dr. Anna Bugge (anbugge@health.sdu.dk), and the following information will be required at the time of application: a description of how the data will be used, securely managed, and permanently deleted.

\section{Authors' contributions}

JT, NCM, NW and AB conceived the study. JT, EJ and HK collected the data. BW analysed the biological samples. All authors formulated the analytical approach. JT performed the analyses and wrote the first draft. All authors read, edited and approved the final manuscript.

\section{Ethics approval and consent to participate}

The CHAMPS-study DK was approved by the ethics committee of the region of southern Denmark (S-20080047 and S-20140105) and written informed consent was obtained from a parent or legal guardian at both time-points.

\section{Competing interests}

The authors declare that they have no competing interests.

\section{Publisher's Note}

Springer Nature remains neutral with regard to jurisdictional claims in published maps and institutional affiliations.

\section{Author details}

${ }^{1}$ Research Unit for Exercise Epidemiology, Centre of Research in Childhood Health, Department of Sports Science and Clinical Biomechanics, University of Southern Denmark, Campusvej 55, 5230 Odense M, Denmark. ${ }^{2}$ Department of Rehabilitation, Odense University Hospital, Institute of Clinical Research, University of Southern Denmark, Odense, Denmark. ${ }^{3}$ University College Lillebælt, Odense, Denmark. ${ }^{4}$ Centre for Sport Science and University Sports, Department of Sports and Exercise Physiology, University of Vienna, Vienna, Austria. ${ }^{5}$ Sports Medicine Clinic, The Orthopedic Department, Hospital of Lillebaelt Middelfart, Institute of Regional Health Research, University of Southern Denmark, Odense, Denmark.

\section{Received: 27 October 2017 Accepted: 27 April 2018}

\section{Published online: 09 May 2018}

\section{References}

1. Berenson GS, Srinivasan SR, Bao W, Newman WP 3rd, Tracy RE, Wattigney WA. Association between multiple cardiovascular risk factors and atherosclerosis in children and young adults. The Bogalusa heart study. N Engl J Med. 1998;338:1650-6.

2. Morrison JA, Friedman LA, Gray-McGuire C. Metabolic syndrome in childhood predicts adult cardiovascular disease 25 years later: the Princeton lipid research clinics follow-up study. Pediatrics. 2007;120:340-5.

3. Ajala O, Mold F, Boughton C, Cooke D, Whyte M. Childhood predictors of cardiovascular disease in adulthood. A systematic review and meta-analysis. Obes Rev. 2017;18(9):1061-70.

4. Franks PW, Hanson RL, Knowler WC, Sievers ML, Bennett PH, Looker HC. Childhood obesity, other cardiovascular risk factors, and premature death. N Engl J Med. 2010;362:485-93.
5. Lee IM, Shiroma EJ, Lobelo F, Puska P, Blair SN, Katzmarzyk PT. Effect of physical inactivity on major non-communicable diseases worldwide: an analysis of burden of disease and life expectancy. Lancet. 2012;380:219-29.

6. Expert Panel on Integrated Guidelines for Cardiovascular Health Risk Reduction in Children and Adolescents, National Heart Lung and Blood Institute. Expert panel on integrated guidelines for cardiovascular health and risk reduction in children and adolescents: summary report. Pediatrics. 2011;128(Suppl 5):S213-56.

7. Dalene KE, Anderssen SA, Andersen LB, Steene-Johannessen J, Ekelund U, Hansen $\mathrm{BH}$, Kolle E. Secular and longitudinal physical activity changes in population-based samples of children and adolescents. Scand J Med Sci Sports. 2017.

8. Tomkinson GR, Olds TS. Secular changes in pediatric aerobic fitness test performance: the global picture. Med Sport Sci. 2007;50:46-66.

9. Moller NC, Wedderkopp N, Kristensen PL, Andersen LB, Froberg K. Secular trends in cardiorespiratory fitness and body mass index in Danish children: the European youth heart study. Scand J Med Sci Sports. 2007;17:331-9.

10. Telama R. Tracking of physical activity from childhood to adulthood: a review. Obes Facts. 2009;2:187-95.

11. NCD Risk Factor Collaboration. Worldwide trends in body-mass index, underweight, overweight, and obesity from 1975 to 2016: a pooled analysis of 2416 population-based measurement studies in 128.9 million children, adolescents, and adults. Lancet. 2017;390(10113):2627-42.

12. White M. Population approaches to prevention of type 2 diabetes. PLoS Med. 2016;13:e1002080.

13. Simmonds M, Llewellyn A, Owen CG, Woolacott N. Predicting adult obesity from childhood obesity: a systematic review and meta-analysis. Obes Rev. 2016;17:95-107.

14. Rose G. Sick individuals and sick populations. Int J Epidemiol. 2001;30:427-32. discussion 433-424

15. Capewell S, Graham H. Will cardiovascular disease prevention widen health inequalities? PLoS Med. 2010;7:e1000320.

16. Batis C, Rivera JA, Popkin BM, Taillie LS. First-year evaluation of Mexico's tax on nonessential energy-dense foods: an observational study. PLoS Med. 2016;13:e1002057

17. Moller N, Tarp J, Kamelarczyk E, Brond J, Klakk H, Wedderkopp N. Do extra compulsory physical education lessons mean more physically active children - findings from the childhood health, activity, and motor performance school study Denmark (the CHAMPS-study DK). Int J Behav Nutr Phys Act. 2014;11:121.

18. Telford RM, Olive LS, Cochrane T, Davey R, Telford RD. Outcomes of a four-year specialist-taught physical education program on physical activity: a cluster randomized controlled trial, the LOOK study. Int J Behav Nutr Phys Act. 2016;13:64.

19. Hollis JL, Sutherland R, Williams AJ, Campbell E, Nathan N, Wolfenden L, Morgan PJ, Lubans DR, Gillham K, Wiggers J. A systematic review and meta-analysis of moderate-to-vigorous physical activity levels in secondary school physical education lessons. Int J Behav Nutr Phys Act. 2017;14:52

20. Hollis JL, Williams AJ, Sutherland R, Campbell E, Nathan N, Wolfenden L, Morgan PJ, Lubans DR, Wiggers J. A systematic review and meta-analysis of moderate-to-vigorous physical activity levels in elementary school physical education lessons. Prev Med. 2016;86:34-54.

21. Cai L, Wu Y, Cheskin LJ, Wilson RF, Wang Y. Effect of childhood obesity prevention programmes on blood lipids: a systematic review and meta-analysis. Obes Rev. 2014;15:933-44.

22. Cai L, Wu Y, Wilson RF, Segal JB, Kim MT, Wang Y. Effect of childhood obesity prevention programs on blood pressure: a systematic review and meta-analysis. Circulation. 2014;129:1832-9.

23. Dobbins M, Husson H, DeCorby K, LaRocca RL. School-based physical activity programs for promoting physical activity and fitness in children and adolescents aged 6 to 18. Cochrane Database Syst Rev. 2013;2:CD007651.

24. Klakk H, Andersen LB, Heidemann M, Moller NC, Wedderkopp N. Six physical education lessons a week can reduce cardiovascular risk in school children aged 6-13 years: a longitudinal study. Scand J Public Health. 2014;42:128-36.

25. Klakk H, Chinapaw M, Heidemann M, Andersen LB, Wedderkopp N. Effect of four additional physical education lessons on body composition in children aged 8-13 years-a prospective study during two school years. BMC Pediatr. 2013;13:170

26. Craig P, Cooper C, Gunnell D, Haw S, Lawson K, Macintyre S, Ogilvie D, Petticrew M, Reeves B, Sutton M, Thompson S. Using natural experiments to evaluate population health interventions: new Medical Research Council guidance. J Epidemiol Community Health. 2012;66:1182-6. 
27. Wedderkopp N, Jespersen E, Franz C, Klakk H, Heidemann M, Christiansen C, Moller NC, Leboeuf-Yde C. Study protocol. The childhood health, activity, and motor performance school study Denmark (the CHAMPS-study DK). BMC Pediatr. 2012;12:128

28. Klakk H. Body composition and cardiovascular health in school-aged children. PhD Thesis. University of Southern Denmark, Department of Sports Science and Clinical Biomechanics and University College Lillebælt; 2013.

29. Pryce R, Willeberg S, Falkentoft C, Meyhoff T. Aldersrelateret træning - Målrettet og forsvarlig træning af børn og unge. 1st ed. Copenhagen: Danmarks Idræts-Forbund. Team Danmark; 2005.

30. Ball GD, Huang TT, Gower BA, Cruz ML, Shaibi GQ, Weigensberg MJ, Goran MI. Longitudinal changes in insulin sensitivity, insulin secretion, and beta-cell function during puberty. J Pediatr. 2006;148:16-22.

31. Jeffery AN, Metcalf BS, Hosking J, Streeter AJ, Voss LD, Wilkin TJ. Age before stage: insulin resistance rises before the onset of puberty: a 9-year longitudinal study (EarlyBird 26). Diabetes Care. 2012;35:536-41.

32. Ahler T, Bendiksen $M$, Krustrup $P$, Wedderkopp N. Aerobic fitness testing in 6- to 9-year-old children: reliability and validity of a modified Yo-Yo IR1 test and the Andersen test. Eur J Appl Physiol. 2012;112:871-6.

33. Aadland E, Terum T, Mamen A, Andersen LB, Resaland GK. The Andersen aerobic fitness test: reliability and validity in 10-year-old children. PLoS One. 2014;9:e110492.

34. Tanner J. Growth at adolescence. 2th ed. Oxford: Blackwell Scientific Publications, and Springfield: Thomas; 1962.

35. Andersen LB, Harro M, Sardinha LB, Froberg K, Ekelund U, Brage S, Anderssen SA. Physical activity and clustered cardiovascular risk in children: a cross-sectional study (the European youth heart study). Lancet. 2006;368:299-304.

36. Matthews DR, Hosker JP, Rudenski AS, Naylor BA, Treacher DF, Turner RC. Homeostasis model assessment: insulin resistance and beta-cell function from fasting plasma glucose and insulin concentrations in man. Diabetologia. 1985;28:412-9.

37. Hjorth MF, Damsgaard CT, Michaelsen KF, Astrup A, Sjodin A. Markers of metabolic health in children differ between weekdays-the result of unhealthier weekend behavior. Obesity (Silver Spring). 2015;23:733-6.

38. Cole TJ, Bellizzi MC, Flegal KM, Dietz WH. Establishing a standard definition for child overweight and obesity worldwide: international survey. BMJ. 2000;320:1240-3

39. Lawlor DA, Harro M, Wedderkopp N, Andersen LB, Sardinha LB, Riddoch CJ, Page AS, Anderssen SA, Froberg K, Stansbie D, Davey Smith G. Association of socioeconomic position with insulin resistance among children from Denmark, Estonia, and Portugal: cross sectional study. BMJ. 2005;331:183.

40. Resaland GK, Anderssen SA, Holme IM, Mamen A, Andersen LB. Effects of a 2-year school-based daily physical activity intervention on cardiovascular disease risk factors: the Sogndal school-intervention study. Scand J Med Sci Sports. 2011:21:e122-31.

41. Kriemler S, Zahner L, Schindler C, Meyer U, Hartmann T, Hebestreit $H_{t}$ Brunner-La Rocca HP, van Mechelen W, Puder JJ. Effect of school based physical activity programme (KISS) on fitness and adiposity in primary schoolchildren: cluster randomised controlled trial. BMJ. 2010;340:C785.

42. Bugge A, El-Naaman B, Dencker M, Froberg K, Holme IM, McMurray RG, Andersen LB. Effects of a three-year intervention: the Copenhagen school child intervention study. Med Sci Sports Exerc. 2012;44:1310-7.

43. Reed KE, Warburton DE, Macdonald HM, Naylor PJ, McKay HA. Action schools! BC: a school-based physical activity intervention designed to decrease cardiovascular disease risk factors in children. Prev Med. 2008:46:525-31.

44. Telford RD, Cunningham RB, Telford RM, Daly RM, Olive LS, Abhayaratna WP. Physical education can improve insulin resistance: the LOOK randomized cluster trial. Med Sci Sports Exerc. 2013;45:1956-64.

45. Kriemler S, Meyer U, Martin E, van Sluijs EM, Andersen LB, Martin BW. Effect of school-based interventions on physical activity and fitness in children and adolescents: a review of reviews and systematic update. Br J Sports Med. 2011:45:923-30.

46. Gonzalez-Suarez C, Worley A, Grimmer-Somers K, Dones V. School-based interventions on childhood obesity: a meta-analysis. Am J Prev Med. 2009;37:418-27.

47. Willi SM, Hirst K, Jago R, Buse J, Kaufman F, El Ghormli L, Bassin S, Elliot D, Hale DE, Group HS. Cardiovascular risk factors in multi-ethnic middle school students: the HEALTHY primary prevention trial. Pediatr Obes. 2012;7:230-9.

48. Hrafnkelsson H, Magnusson KT, Thorsdottir I, Johannsson E, Sigurdsson EL. Result of school-based intervention on cardiovascular risk factors. Scand J Prim Health Care. 2014;32:149-55.
49. Naylor PJ, Nettlefold L, Race D, Hoy C, Ashe MC, Wharf Higgins J, McKay HA. Implementation of school based physical activity interventions: a systematic review. Prev Med. 2015;72:95-115.

50. Kipping RR, Howe LD, Jago R, Campbell R, Wells S, Chittleborough CR, Mytton J, Noble SM, Peters TJ, Lawlor DA. Effect of intervention aimed at increasing physical activity, reducing sedentary behaviour, and increasing fruit and vegetable consumption in children: active for life year 5 (AFLY5) school based cluster randomised controlled trial. BMJ. 2014;348:g3256.

51. Meyer U, Schindler C, Zahner L, Ernst D, Hebestreit H, van Mechelen W Brunner-La Rocca HP, Probst-Hensch N, Puder JJ, Kriemler S. Long-term effect of a school-based physical activity program (KISS) on fitness and adiposity in children: a cluster-randomized controlled trial. PLoS One. 2014:9:e87929

52. Kafatos I, Manios Y, Moschandreas J, Kafatos A, Preventive M. Nutrition clinic University of Crete Research $\mathrm{T}$ : health and nutrition education program in primary schools of Crete: changes in blood pressure over 10 years. Eur J Clin Nutr. 2007:61:837-45.

53. Manios Y, Kafatos A, Preventive M. Nutrition clinic University of Crete Research T: health and nutrition education in primary schools in Crete: 10 years follow-up of serum lipids, physical activity and macronutrient intake. Br J Nutr. 2006;95:568-75.

54. Burke V, Milligan RA, Thompson C, Taggart AC, Dunbar DL, Spencer MJ, Medland A, Gracey MP, Vandongen R, Beilin L. A controlled trial of health promotion programs in 11-year-olds using physical activity "enrichment" for higher risk children. J Pediatr. 1998;132:840-8.

55. Hardy ST, Loehr LR, Butler KR, Chakladar S, Chang PP, Folsom AR, Heiss G, MacLehose RF, Matsushita K, Avery CL. Reducing the blood pressure-related burden of cardiovascular disease: impact of achievable improvements in blood pressure prevention and control. J Am Heart Assoc. 2015;4:e002276.

56. Dehmer SP, Maciosek MV, LaFrance AB, Flottemesch TJ. Health benefits and cost-effectiveness of asymptomatic screening for hypertension and high cholesterol and aspirin counseling for primary prevention. Ann Fam Med. 2017;15:23-36.

57. GBD Risk Factors Collaborators. Global, regional, and national comparative risk assessment of 84 behavioural, environmental and occupational, and metabolic risks or clusters of risks, 1990-2016: a systematic analysis for the global burden of disease study 2016. Lancet. 2017;390:1345-422.

58. Wang YC, Cheung AM, Bibbins-Domingo K, Prosser LA, Cook NR, Goldman L, Gillman MW. Effectiveness and cost-effectiveness of blood pressure screening in adolescents in the United States. J Pediatr. 2011:158:257-64. e251-257

59. Oosterhoff $M$, Joore M, Ferreira I. The effects of school-based lifestyle interventions on body mass index and blood pressure: a multivariate multilevel meta-analysis of randomized controlled trials. Obes Rev. 2016;17:1131-53.

60. Haapala HL, Hirvensalo MH, Kulmala J, Hakonen H, Kankaanpaa A, Laine K, Laakso L, Tammelin TH. Changes in physical activity and sedentary time in the Finnish schools on the move program: a quasi-experimental study. Scand J Med Sci Sports. 2017;27:1442-53.

61. Hebert JJ, Klakk H, Moller NC, Grontved A, Andersen LB, Wedderkopp N. The prospective Association of Organized Sports Participation with Cardiovascular Disease Risk in children (the CHAMPS study-DK). Mayo Clin Proc. 2017;92:57-65

62. Wang Y, Cai L, Wu Y, Wilson RF, Weston C, Fawole O, Bleich SN, Cheskin LJ, Showell NN, Lau BD, et al. What childhood obesity prevention programmes work? A systematic review and meta-analysis. Obes Rev. 2015;16:547-65.

63. Brown HE, Corder K, Atkin AJ, van Sluijs EM. Childhood predictors of adolescent behaviour: the prospective association of familial factors with meeting physical activity guidelines. Prev Med Rep. 2017;6:221-7.

64. Muellmann S, Steenbock B, De Cocker K, De Craemer M, Hayes C, O'Shea MP, Horodyska K, Bell J, Luszczynska A, Roos G, et al. Views of policy makers and health promotion professionals on factors facilitating implementation and maintenance of interventions and policies promoting physical activity and healthy eating: results of the DEDIPAC project. BMC Public Health. 2017;17:932

65. Borde R, Smith JJ, Sutherland R, Nathan N, Lubans DR. Methodological considerations and impact of school-based interventions on objectively measured physical activity in adolescents: a systematic review and meta-analysis. Obes Rev. 2017;18:476-90.

66. Metcalf $B$, Henley W, Wilkin T. Effectiveness of intervention on physical activity of children: systematic review and meta-analysis of controlled trials with objectively measured outcomes (EarlyBird 54). BMJ (Online). 2012:345:1-11. 
67. Sims J, Scarborough P, Foster C. The effectiveness of interventions on sustained childhood physical activity: a systematic review and meta-analysis of controlled studies. PLoS One. 2015;10:e0132935.

68. Mears R, Jago R. Effectiveness of after-school interventions at increasing moderate-to-vigorous physical activity levels in 5- to 18-year olds: a systematic review and meta-analysis. Br J Sports Med. 2016;50(21):1315-24

69. Glymour MM, Weuve J, Berkman LF, Kawachi I, Robins JM. When is baseline adjustment useful in analyses of change? An example with education and cognitive change. Am J Epidemiol. 2005;162:267-78.

Ready to submit your research? Choose BMC and benefit from:

- fast, convenient online submission

- thorough peer review by experienced researchers in your field

- rapid publication on acceptance

- support for research data, including large and complex data types

- gold Open Access which fosters wider collaboration and increased citations

- maximum visibility for your research: over $100 \mathrm{M}$ website views per year 